\title{
Patient aggression towards different professional groups of healthcare workers
}

\author{
Krystyna Kowalczuk', Elżbieta Krajewska-Kułak' \\ ${ }^{1}$ Department of Integrated Medical Care, Medical University of Bialystok, Poland
}

Kowalczuk K, Krajewska-Kułak E. Patient aggression towards different professional groups of healthcare workers. Ann Agric Environ Med. 2017; 24(1): 113-116. doi: 10.5604/12321966.1228395

\begin{abstract}
Introduction. Patient aggression affects healthcare quality and, in extreme situations, may even lead to medical malpractice. Little is known, however, about the specific distribution of health care professionals' exposure to patient aggression in various countries.

Objective. The aim of this study was to assess the exposure of various professional groups of healthcare personnel to patient aggression, and to identify potential determinants (medical profession, age, gender, professional experience and employment at outpatient/inpatient healthcare units) of this exposure.

Methods. The study was performed between January 2008 - December 2009 in northeastern Poland, and included 1,624 healthcare workers (493 nurses, 504 midwives, 501 physicians and 126 medical rescue workers). Exposure to eight forms of patient aggression was assessed using the MDM Mobbing Questionnaire.

Results. Using a raised voice was the most frequently observed form of aggression in all groups, whereas the least frequent form of aggression encountered was the use of direct physical violence. In inpatient healthcare units, the intensity of patient aggression was encountered most by nurses and medical rescue workers, followed by physicians and midwives. In outpatient healthcare units, medical rescue workers experienced significantly higher levels of aggression when compared to other professional groups. Significant differences in mean aggression intensity experienced in inpatient and outpatient healthcare units were observed only in nurses and physicians. Furthermore, no significant effects of gender were observed on the intensity of patient aggression.

Conclusion. Nurses are most exposed to different forms of patient aggression, with verbal attacks being most prevalent. Nurses employed at inpatient healthcare units experienced aggression more frequently than those working in outpatient healthcare units.
\end{abstract}

\section{Key words}

aggression, stress, nurse, midwife, physician, medical rescue worker

\section{INTRODUCTION}

The European Commission defines aggression at a workplace as: 'all situations when a worker is offended, threatened or attacked in conditions directly related to his/her job and when these situations directly or indirectly endanger his/ her safety, welfare and health' [1]. Aggressive behaviours may have various forms and intensities: ranging from verbal aggression to direct violence [2].

Aggression is not a new phenomenon within the working environment, but it is only of late that its consequences are being fully realized. Aggression affects not only the functioning of individual workers but also the efficiency of the entire organization. Occupational exposure to aggressive behaviours is associated with an increased level of stress which, in turn, affects the workers' ability to execute their duties [3].

Aggression in healthcare is particularly problematic. According to the International Labour Organization, healthcare workers are ranked second with regards to their exposure to violence at their workplace. Besides aggression encountered from their co-workers, healthcare personnel are also markedly exposed to patient aggression [4].

Address for correspondence: Krystyna Kowalczuk, Department of Integrated Medical Care, Medical University of Białystok, M. Skłodowskiej-Curie 7A, 15-096 Bialystok, Poland

E-mail:kkowalczuk@op.pl

Received: 16 July 2013; accepted: 21 January 2014; first published on December, 2016
Patient aggression has a complex etiology. Undoubtedly, one of its primary reasons is stress related to health deficits, dependence on healthcare personnel and, in some cases, the necessity for hospitalization. Levels of aggression are also influenced by different types of diseases; for instance, aggression is more frequent amongst emergency and psychiatric patients $[5,6]$. In the case of public healthcare in Poland, these aforementioned factors are overlapped by specific considerations regarding the healthcare system. The inefficiency of this system is reflected by long waiting times for healthcare services, together with their limited availability.

Besides its negative effects on the mental status of healthcare workers and their level of job satisfaction, patient aggression affects healthcare quality and may, in extreme situations, be the cause of medical malpractice [7]. Consequently, monitoring aggression levels and their reasons in healthcare institutions is of crucial importance. Little is known, however, about the specific distribution of health care professionals' exposure to patient aggression in various countries.

\section{OBJECTIVE}

The aim of this study was to assess the exposure of various professional groups of healthcare personnel to patient aggression, and to identify potential determinants (medical 
profession, age, gender, professional experience and employment at outpatient/inpatient healthcare units) of this exposure.

\section{MATERIALS AND METHOD}

A correlational design was used for the study which was performed between January 2008 - December 2009 during continued education courses delivered in the area of the Podlaskie Province in north-eastern Poland. The study comprised 1,624 healthcare workers (78.6\% response rate), among them 493 nurses, 504 midwives, 501 physicians, and 126 medical rescue workers (paramedics). Respondents were asked to complete the MDM Mobbing Questionnaire, developed at the Department of Occupational Psychology of the Nofer Institute of Occupational Medicine in Lodz, Poland. The questionnaire was developed in order to examine the frequency of aggression within the workplace. It contains 56 questions (32 diagnostic and 24 additional questions) pertaining to various aggressive behaviours the respondents may experience at work, perpetrated against their superiors, co-workers and customers. Exposure to eight forms of patient aggression are assessed, including: 1) raised voice, 2) threats, 3) blackmail, 4) attempts to strike, 5) dangerous attitudes, 6) aggression in the presence of healthcare personnel, 7) aggression in the presence of other patients, and 8) use of direct physical violence. The answers to these questions are graded using a six-point frequency scale where 0 corresponds to 'never' and 5 - to 'at least once a week'. The sum of the points for all forms of aggression is considered as the overall intensity of experienced aggression [8].

Ethical considerations. Participation in this study was voluntarily and the study was accepted by the Local Bioethical Committee at the Medical University of Bialystok. The participants gave their written informed consent before completing the questionnaire.

Data analysis. Continuous variables were presented as arithmetic means and their standard deviations (SD). Their normal distribution was tested using the Shapiro-Wilk test. Arithmetic means amongst multiple groups were compared using the ANOVA and the Tukey post-hoc tests, and multiple regression was used to verify the effects of employment at outpatient or inpatient healthcare units, gender, age, and professional experience on the levels of aggression experienced in analyzed professional groups. Distributions of qualitative variables were compared by means of the Pearson's chi-square test of Fischer's exact test. Calculations were performed using Statistica 7 (StatSoft, Poland) software, with statistical significance defined as $P \leq 0.05$.

\section{RESULTS}

Detailed characteristics of the study participants are summarized in Table 1 . The professional subgroups differed significantly in terms of mean age and professional experience, together with the distribution of genders and employment at outpatient and inpatient healthcare units.

Using a raised voice was the most frequently observed form of patient aggression in all professional groups, whereas
Table 1. Characteristics of study participants

\begin{tabular}{lccccc}
\hline Parameter & $\begin{array}{c}\text { Nurses } \\
(\mathrm{n}=493)\end{array}$ & $\begin{array}{c}\text { Midwives } \\
(\mathrm{n}=504)\end{array}$ & $\begin{array}{c}\text { Physicians } \\
(\mathrm{n}=500)\end{array}$ & $\begin{array}{c}\text { Rescue } \\
\text { workers } \\
(\mathrm{n}=126)\end{array}$ & $P^{*}$ \\
\hline Women & $481(97.57 \%)$ & $502(99.60 \%)^{\mathrm{a}}$ & $281(56.20 \%)^{\mathrm{b}}$ & $37(29.37 \%)^{\mathrm{c}}$ & $<0.001$ \\
\hline Age (years) & $37.58 \pm 7.51$ & $39.46 \pm 6.42^{\mathrm{a}}$ & $39.47 \pm 9.38^{\mathrm{a}}$ & $30.60 \pm 8.50^{\mathrm{b}}$ & $<0.001$ \\
\hline $\begin{array}{l}\text { Experience } \\
\text { years) }\end{array}$ & $15.41 \pm 8.02$ & $16.81 \pm 7.27^{\mathrm{a}}$ & $13.61 \pm 9.45^{\mathrm{b}}$ & $6.11 \pm 6.12^{\mathrm{c}}$ & $<0.001$ \\
\hline $\begin{array}{l}\text { Outpatient } \\
\text { Clinics }\end{array}$ & $167(33.87 \%)$ & $75(14.88 \%)^{\mathrm{a}}$ & $102(20.4 \%)^{\mathrm{b}}$ & $65(51.59)^{\mathrm{c}}$ & $<0.001$ \\
\hline $\begin{array}{l}\text { *-Pearson's chi-square test or Fisher's exact test; } \\
\text { a,b,c }- \text { significant differences between subgroups }\end{array}$ & & & \\
\hline
\end{tabular}

the least frequently observed forms of patient aggression were the use of direct physical violence or its attempt (attempt to strike). Significant differences were observed among the groups regarding the frequency of their exposure to patients using a raised voice or threats, and those exhibiting aggressive behaviours in the presence of healthcare personnel or other patients (Tab. 2). Patients used raised voices significantly more frequently when communicating with nurses or medical rescue workers, whereas midwives were exposed to this form of aggression least frequently out of all of the professional group studied. The frequency of patient threats towards nurses was significantly higher than in the case of the remaining professional groups. Nurses and medical rescue workers were exposed to patient aggression in the presence of healthcare personnel more frequently than other healthcare workers. Additionally, nurses experienced aggression in the presence of other patients significantly more frequently than other healthcare personnel. This form of aggression was least frequently encountered by midwives.

Table 2. Number and percentage of representatives of various medical personnel being exposed to different forms of patient aggression at least several times a week

\begin{tabular}{lccccc}
\hline $\begin{array}{l}\text { Form of } \\
\text { aggression }\end{array}$ & $\begin{array}{c}\text { Nurses } \\
(n=493)\end{array}$ & $\begin{array}{c}\text { Midwives } \\
(n=504)\end{array}$ & $\begin{array}{c}\text { Physicians } \\
(n=500)\end{array}$ & $\begin{array}{c}\text { Rescue } \\
\text { workers } \\
(n=126)\end{array}$ & $P^{*}$ \\
\hline Raised voice & $181(36.71 \%)$ & $65(12.90 \%)^{\mathrm{a}}$ & $108(21.60 \%)^{\mathrm{b}}$ & $37(29.37 \%)$ & $<0.001$ \\
\hline Threats & $74(15.01 \%)$ & $28(5.56 \%)^{\mathrm{a}}$ & $40(8.00 \%)^{\mathrm{a}}$ & $12(9.52 \%)^{\mathrm{a}}$ & $<0.001$ \\
\hline Blackmail & $32(6.49 \%)$ & $24(4.76 \%)$ & $21(4.20 \%)$ & $6(4.76 \%)$ & 0.411 \\
\hline $\begin{array}{l}\text { Attempt to } \\
\text { strike }\end{array}$ & $24(4.87 \%)$ & $18(3.57 \%)$ & $16(3.20 \%)$ & $3(2.38 \%)$ & 0.422 \\
\hline $\begin{array}{l}\text { Dangerous } \\
\text { attitude }\end{array}$ & $51(10.34 \%)$ & $22(4.37 \%)^{\mathrm{a}}$ & $35(7.00 \%)$ & $12(9.52 \%)$ & 0.003 \\
\hline $\begin{array}{l}\text { Aggression } \\
\text { in presence } \\
\text { of personnel }\end{array}$ & $93(18.86 \%)$ & $26(5.16 \%)^{\mathrm{a}}$ & $41(8.20 \%)^{\mathrm{a}}$ & $20(15.87 \%)$ & $<0.001$ \\
\hline $\begin{array}{l}\text { Aggression } \\
\text { in presence } \\
\text { of patients }\end{array}$ & $91(18.46 \%)$ & $24(4.76 \%)^{\mathrm{a}}$ & $37(7.40 \%)^{\mathrm{b}}$ & $13(10.32 \%)^{\mathrm{b}}$ & $<0.001$ \\
\hline $\begin{array}{l}\text { Physical } \\
\text { violence }\end{array}$ & $5(1.01 \%)$ & $16(3.17 \%)$ & $9(1.80 \%)$ & $2(1.59 \%)$ & 0.102 \\
\hline
\end{tabular}

*Pearson's chi-square test or Fisher's exact test, ${ }^{\mathrm{a}, \mathrm{b}, \mathrm{c}}$ significant differences between the groups

The mean intensity of patient aggression towards nurses or medical rescue workers was significantly higher than towards physicians. The lowest intensity of aggression was directed to midwives; these relationships were also observed in the subgroup of personnel employed at inpatient healthcare units. In outpatient healthcare units, however, medical 
rescue workers experienced significantly higher levels of aggression compared to other professional groups. Significant differences in mean aggression intensity experienced in inpatient and outpatient healthcare units were observed only in the subgroups of nurses and physicians (Tab. 3).

In women, a significantly higher exposure to aggression was observed in nurses and medical rescue workers, while the lowest levels of aggression were noted amongst midwives. Due to the high disproportion of gender, a similar analysis was not performed for male workers. No significant effects of gender were observed on the intensity of patient aggression among any of the professional groups studied (Tab. 3).

A significant inverse correlation between participant age or professional experience and the level of exposure to patient aggression was confirmed only amongst physicians (Tab. 3).

Table 3. Mean ( \pm standard deviation) intensity of patient aggression towards representatives of various medical personnel stratified by place of work, gender, age and professional experience

\begin{tabular}{|c|c|c|c|c|c|}
\hline $\begin{array}{l}\text { Grouping } \\
\text { variable }\end{array}$ & $\begin{array}{l}\text { Nurses } \\
(n=493)\end{array}$ & $\begin{array}{c}\text { Midwives } \\
(n=504)\end{array}$ & $\begin{array}{c}\text { Physicians } \\
(n=500)\end{array}$ & $\begin{array}{l}\text { Rescue } \\
\text { workers } \\
(n=126)\end{array}$ & $P^{*}$ \\
\hline \multicolumn{6}{|l|}{ Employment } \\
\hline Overall & $26.80 \pm 20.85$ & $12.04 \pm 17.61^{\mathrm{a}}$ & $18.57 \pm 18.58^{b}$ & $26.59 \pm 18.25$ & $<0.001$ \\
\hline $\begin{array}{l}\text { Outpatient } \\
\text { clinics }\end{array}$ & $20.21 \pm 19.89$ & $15.04 \pm 19.19$ & $15.87 \pm 12.58$ & $28.08 \pm 17.75^{\mathrm{a}}$ & $<0.001$ \\
\hline $\begin{array}{l}\text { Inpatient } \\
\text { clinics }\end{array}$ & $30.19 \pm 20.56$ & $11.52 \pm 17.30^{\mathrm{a}}$ & $19.24 \pm 19.80^{b}$ & $25.00 \pm 18.78$ & $<0.001$ \\
\hline$P^{* *}$ & $<0.001$ & 0.141 & 0.048 & 0.164 & - \\
\hline \multicolumn{6}{|l|}{ Gender } \\
\hline Women & $26.60 \pm 20.86$ & $12.05 \pm 17.64^{\mathrm{a}}$ & $17.84 \pm 19.01^{b}$ & $30.15 \pm 26.09$ & $<0.001$ \\
\hline Men & $34.90 \pm 19.62$ & $10.94 \pm 11.05$ & $19.72 \pm 18.06^{a}$ & $25.11 \pm 13.68$ & NA \\
\hline$P^{* *}$ & 0.257 & 0.971 & 0.278 & 0.076 & \\
\hline Age $\left(P^{* *}\right)$ & 0.532 & 0.440 & 0.004 & 0.113 & - \\
\hline $\begin{array}{l}\text { Experience } \\
\left(P^{* *}\right)\end{array}$ & 0.733 & 0.665 & 0.001 & 0.909 & - \\
\hline
\end{tabular}

*ANOVA, a,bsignificant differences between the groups (Tukey post-hoc test), **multiple regression, NA - not analyzed.

\section{DISCUSSION}

The subjective attitude to the term 'aggression' was one potential limitation of this study, together with the recall bias typically associated with retrospective surveys. Nonetheless, using the standardized questionnaire, a significant variability was observed in the types and levels of patient aggression experienced by different professional groups of healthcare workers.

Verbal aggression in the form of using a raised voice was the most frequent form of aggression encountered by all of the studied groups. Previous European studies confirm that verbal aggression is the most frequent form of patient aggression towards healthcare personnel. According to various authors, the frequency of exposure of healthcare workers to this form of aggression ranges from more than $60 \%$ to nearly $90 \%[5,6,9,10,11]$.

In the presented study, verbal aggression was more frequently experienced by nurses and medical rescue workers than by other professional groups. However, the etiology of exposure of these two groups to verbal aggression was plausibly different. It should be remembered that nurses constitute the professional group with whom patients interact most frequently; consequently, nurses bear the brunt of most of the patients' frustrations. This was confirmed in the current study by significant differences in the exposure to aggression between nurses employed at outpatient and inpatient healthcare units. The level of exposure in this latter group was significantly higher, resulting from the fact that patients treated at outpatient clinics contact nurses less frequently compared to hospitalized patients. The highest level of patient aggression experienced by nurses was previously confirmed in other countries. According to various authors, in most countries the frequency of this group's exposure to aggression amounts to about $50 \%$, and is therefore similar to the frequency determined in the presented study $[10,11,12]$.

Medical rescue workers, in turn, meet patients in specific situations - emergency, frequently life-threatening conditions. Consequently, higher levels of aggression experienced by this group might be explained in the context of how patients and their relatives behave under stressful conditions. Searching through the available literature, no foreign articles were found dealing with the exposure of medical rescue workers to patient aggression. However, the results of studies performed among different groups of personnel employed at emergency units suggest that their exposure is higher than in healthcare workers dealing with scheduled patients $[5,6]$.

The lower exposure of midwives to patient aggression observed in the current study seems to have a complex etiology. Usually, patients contact midwives during the perinatal period; therefore, this contact is planned and expected, and pregnant woman (and their spouses) prepare for it for a longer period of time. Moreover, deliveries are more frequently conducted by midwives, often after having already met the pregnant women or having been employed by them. Finally, it should be remembered that women constitute the majority of midwifery patients, and according to many studies, the level of aggression represented by this gender is significantly lower than in males [11]. Available literature lacks data on the exposure of midwives to aggression in other countries. Therefore, it is likely that the problem of patient aggression towards midwives is of marginal importance in other countries.

In the case of physicians participating in this study, the levels of experienced patient aggression were significantly lower than in nurses or medical rescue workers. However, levels of exposure were higher than in midwives. In Western European countries, the exposure of physicians to patient aggression is the lowest out of all healthcare workers $[6,10]$. According to the literature, exposure of physicians to patient aggression is inhomogeneous and related to their specialty and employment. Exposure to violence is significantly higher among personnel working with psychiatric and geriatric patients, as well as in emergency units $[5,6,9,11,12,13]$. Unfortunately, the design of the presented study did not allow for distinguishing subgroups employed in these specific settings among the physicians.

The study evealed that the gender of healthcare personnel has no influence on the level of patient aggression experienced; however, the lack of this relationship in the analyzed professional groups was mostly related to a high gender disproportion in favour of women. Among all the studied groups, only physicians presented with a gender distribution that was relatively homogeneous. Nonetheless, gender-related differences in levels of experienced aggression 
were also not observed in this group - presumably due to the generally low level of exposure of physicians to aggression and the inhomogeneity of this group in terms of employment and specialization. As previously mentioned, the latter two factors are significant determinants of the level of experienced aggression. According to the results of an Italian study, women are more frequently exposed to patient aggression - mostly verbal in nature [11]. This observation, however, should be interpreted with care, with specific local cultural considerations kept in mind.

It was also observed in the presented study that exposure to aggression slightly but significantly decreased with the age of healthcare personnel and their professional experience. There are two possible explanations for this relationship. Gains in professional experience may be reflected by higher levels of personnel involvement in taking care of patients and thus increased patient satisfaction. However, more-experienced personnel may also ignore the aggressive behaviours of patients and, as such, these behaviours may not have been fully reported in this study.

The current study also confirmed that, like in other European countries, the problem of patient aggression exists amongst Polish healthcare personnel and occurs at similar levels. Although the respondents rarely reported episodes of direct physical violence used against them by their patients, it should be kept in mind that exposure to other forms of aggression may also impair the functioning of healthcare units, as well as patient safety and comfort. Literature data suggests significant association between the frequency of patient aggression towards healthcare personnel and the presence of feelings of fatigue, stress or lack of satisfaction with work $[5,7,11]$.

Consequently, it is necessary to reduce the level of patient aggression observed in healthcare units. The first step in achieving this goal should be determination of the real scale of the problem of patient aggression and its sources. This is not a simple task. Frequently, healthcare personnel hold a rather passive attitude towards patient aggression and do not report it to their superiors. According to literature, this happens in more than half of cases [11]. Nonetheless, every healthcare unit should keep a register of aggressive patient behaviours - much as in the case of exposures to other occupational harmful factors. This register may serve as a source of knowledge used to prevent similar episodes in the future, or as an exhibit in the case of possible lawsuits [14]. The lack of such registers will not be remedied by surveys similar to the presented study. Such studies are performed only periodically and confounded by marked recall bias and will not reveal any individual causative relationships [15].

The second aspect to consider in preventing patient aggression is the implementation of specific programmes and procedures oriented towards limiting aggression at the workplace, and personnel education in coping with stress and dealing with aggressive patients. The efficiency of these solutions has been confirmed by several studies $[12,15,16$, 17, 18].

Bearing in mind that nurses are more often than not the victims of patient aggression, activities should be undertaken aimed at building the proper position of this professional group amongst healthcare personnel. One possible step towards achieving this goal is to enable nurses to improve their education, including having access to university studies and continuous education - systemic solutions that for several years have gradually and more effectively been implemented in Poland.

Finally, the implementation of systemic changes in the Polish healthcare system would be the optimal solution, resulting in increased satisfaction of the patients, and higher professional motivation of healthcare personnel.

\section{CONCLUSION}

Nurses represent a part of the medical profession which is most exposed to different forms of patient aggression. The most prevalent form of the aggression is verbal attack, manifested by the use of a raised voice. Nurses employed at inpatient healthcare units experience aggression more frequently than their colleagues working in outpatient healthcare units.

\section{REFERENCES}

1. European Commission. Opinion of the Advisory Committee on Safety, Hygiene and Health Protection at Work on Violence at the workplace DOC 1564/2/2001 EN. 2001.

2. Kowalczuk K, Krajewska-Kułak E, Kułak W, Ostapowicz-Van Damme $\mathrm{K}$, Klimaszewska K, Rolka H. Influence of aggression on stress development in the population of nurses and midwives in the Podlaskie Province. Probl Hig Epidemiol 2010; 91(3): 444-450.

3. Merecz D, Drabek M, Moscicka A. Aggression at the workplace-psychological consequences of abusive encounter with coworkers and clients. Int J Occup Med Environ Health. 2009; 22(3): 243-260.

4. Hoel H, Sparks K, Cooper CL. The cost of violence/stress at work and the benefits of a violence/stress-free working environment. Geneva, Report commissioned by the International Labour Organization, 2001.

5. Fernandes CM, Bouthillette F, Raboud JM, Bullock L, Moore CF, Christenson JM, et al. Violence in the emergency department: a survey of health care workers. CMAJ. 1999; 161(10): 1245-1248.

6. Franz S, Zeh A, Schablon A, Kuhnert S, Nienhaus A. Aggression and violence against health care workers in Germany--a cross sectional retrospective survey. BMC Health Serv Res. 2010; 10: 51.

7. Bonner G, McLaughlin S. The psychological impact of aggression on nursing staff. Br J Nurs. 2007; 16(13): 810-814.

8. Dudek B, Waszkowska M, Merecz D, Hanke W. Worker's health protection against the consequences of occupational stress. Łódź, Instytut Medycyny Pracy, 2004.

9. Dean AJ, Gibbon P, McDermott BM, Davidson T, Scott J. Exposure to aggression and the impact on staff in a child and adolescent inpatient unit. Arch Psychiatr Nurs. 2010; 24(1): 15-26.

10. Winstanley S, Whittington R. Aggression towards health care staff in a UK general hospital: variation among professions and departments. J Clin Nurs. 2004; 13(1): 3-10.

11. Zampieron A, Galeazzo M, Turra S, Buja A. Perceived aggression towards nurses: study in two Italian health institutions. J Clin Nurs. 2010; 19(15-16): 2329-2341.

12. Josefsson K, Ryhammar L. Threats and violence in Swedish community elderly care. Arch Gerontol Geriatr. 2010; 50(1): 110-113.

13. Yarovitsky Y, Tabak N. Patient violence towards nursing staff in closed psychiatric wards: it's long-term effects on staff's mental state and behaviour. Med Law. 2009; 28(4): 705-724.

14. Garcia-Calvo T, Guijarro R, Osun E. The phenomenon of physical aggression against health service personnel: different perspectives. Med Law. 2009; 28(3): 451-459.

15. Chapman R, Perry L, Styles I, Combs S. Predicting patient aggression against nurses in all hospital areas. Br J Nurs. 2009; 18(8): 476, 478-483.

16. Deans C. The effectiveness of a training program for emergency department nurses in managing violent situations. Aust J Adv Nurs. 2004; 21(4): 17-22.

17. Finfgeld-Connett D. Model of therapeutic and non-therapeutic responses to patient aggression. Issues Ment Health Nurs. 2009; 30(9): $530-537$.

18. McLaughlin S, Bonner G, Mboche C, Fairlie T. A pilot study to test an intervention for dealing with verbal aggression. Br J Nurs. 2010; 19(8): 489-494. 